\title{
MARTÍN FERNÁNDEZ DE NAVARRETE (1765-1844) Y JOSÉ MUSSO VALIENTE (1785-1838), UNA RELACIÓN CULTURAL Y ACADÉMICA
}

\author{
José Luis Molina Martínez \\ Académico Correspondiente de la Real Academia de Alfonso X el Sabio
}

\section{Generalidades}

En el plano de las ideas y en su manifestación en la actividad socio-intelectual que, poco a poco, abrió el camino de la modernidad, aunque se pagó un precio excesivo, cual fue la pérdida de los ideales y las prácticas humanísticos que ambos sabios profesaban, en beneficio de una laicidad liberal o un liberalismo laico, existen demasiados hombres (nombres) cuya contribución fue decisiva, más o menos, según su obra. Sin embargo, no son nombres (hombres) conocidos para el gran público y de ellos apenas se ocupan ni los especialistas del siglo XIX ni del liberalismo.

En el caso que nos ocupa, vamos a tratar de dos personajes, mejor expresado aún, de las relaciones entre estos dos personajes, de las que se desprenden trabajos de una u otra parte, comunes, de superior a subordinado, que sirvieron para el progreso de las ciencias, la literatura y las artes, entre 1825 y 1837.

La bibliografía que ha llegado a mis manos casi nunca los relaciona y, cuando lo hace, aparecen más bien de forma encontrada, al menos en un caso en el que 
bloquearon (Navarrete y Clemencín $\left.{ }^{2}\right)$ una iniciativa de Musso, como veremos a continuación ${ }^{3}$.

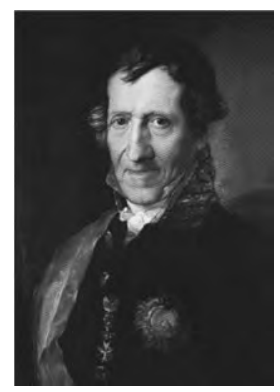

Figura 1: Martín Fernández de Navarrete4.

Sobre Martín Fernández de Navarrete, en verdad, existe más bibliografía por haber ocupado puestos en cierto modo preeminentes en la administración, en la marina y en las distintas Academias a las que ambos pertenecieron. Ya en vida, se escribe su primera biografía ${ }^{5}$. Otros textos aparecen en la bibliografía que manejo ${ }^{6}$.

1. Sabemos de la existencia de correspondencia entre Navarrete y Musso porque son cinco las cartas que se custodian en Mula (Biblioteca Archivo de la Caja de Ahorros de Mediterráneo, BACAM), escritas entre el 27 de julio de 1830 y el 31 de octubre de 1834, y que iré dando a conocer a lo largo de este escrito. Es posible que se encuentren las cartas de Musso entre los papeles conservados de Fernández de Navarrete y que nadie se haya ocupado de ellas por el desconocimiento que existe sobre la figura de José Musso.

2. Vid., José Luis Molina Martínez, "Contestaciones de Clemencín a cartas de José Musso Valiente (1829-1833)", en Murgetana, 105, Academia Alfonso X el Sabio, 2001, pp. 57-62.

3. Vid., Jorge Maier Allende, "La comisión de Antigüedades de la Real Academia de la Historia", en Martín Almagro Gorbea y Jorge Maier Allende (eds.), 250 años de Arqueología y Patrimonio, Madrid, 2003, pp. 25-51, y M. Almagro-Gorbea y J. Maier, "El futuro desde el pasado: la Real Academia de la Historia y el origen y funciones del Museo Arqueológico Nacional". Boletín de la Real Academia de la Historia, CXCVI, p. 183-207.

4. Retrato conservado en el Museo Naval.

5. Vid., Gonzalo Morón, "D. Martín Fernández de Navarrete", en (Nicomedes Pastor DíazFrancisco Cárdenas, eds.) Galería de españoles célebres contemporáneos, Madrid, Imprenta de don Ignacio Boix, Tomo I, 1841.

6. Vid., Jesús Cañedo Fernández, "Martín Fernández de Navarrete, crítico literario. Un joven marino y la literatura a finales del siglo XVIII", en (Eugenio Bustos Tovar, coord.) Actas del IV Congreso Internacional de Hispanistas, Salamanca, Universidad de Salamanca, vol. I, 1982, pp. 243-254, y Jesús Fernando Cáseda Teresa, Martín Fernández de Navarrete y la literatura de su tiempo, Logroño, IER, 2000. 


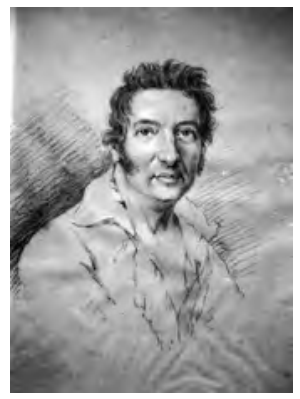

Figura 2: José Musso Valiente, por José de la Revilla, 1831.

Por el otro lado, aunque a Musso también le escribieron una biografía el mismo año de su fallecimiento ${ }^{7}$ y pocos después Francisco de Cárdenas escribiera otra pródiga en recuerdos infantiles y estudiantiles ${ }^{8}$, a partir de esta fecha, una oscura losa, la del olvido, cayó sobre Musso y sólo hacia el año 1998 se ha procedido a recuperar su memoria9 .

Musso Ilega a Madrid en 1797 para estudiar en el Colegio de San Fernando de Avapiés, de los Hermanos de las Escuelas Pías, cuando Navarrete, veinte años mayor, estaba ya instalado en la capital. Concluidos sus estudios, regresa a Lorca y sólo vuelve a la Corte tras su exilio en Gibraltar, 1823. En Madrid vive hasta el 30 de junio de 1830. Si esta época es fecunda intelectualmente para Musso, en la que conoce a Martín Fernández de Navarrete, tras su paso por la política, fue Subdelegado Principal de Fomento en Murcia y Gobernador Civil

7. Vid., Fermín de la Puente y Apezechea, "Memoria biográfica del Sr. D. José Musso Valiente", en Revista de Madrid, tomo II, 15 de octubre de 1838, pp. 119-168, y A la grata memoria del señor D. José Musso Valiente para gloria y ejemplo de los suyos, recuerdo de sus amigos y gratitud de la Patria, consagra esta noticia de su vida, su hijo, discípulo y mejor amigo Fermín de la Puente y Apezechea, Madrid, Oficina de D. Tomás Jordán, impresor de Cámara de S. M., 1838.

8. Vid., Francisco de Cárdenas, "D. José Musso Valiente", en Galería de españoles célebres contemporáneos o biografías y retratos de todos los personajes distinguidos de nuestros días en las ciencias, en la política, en las armas, en las letras y en las artes, publicadas por D. Nicomedes Pastor Díaz y Francisco de Cárdenas. Tomo VII. Madrid. Imprenta y Librería de D. Ignacio Boix, editor, calle de Carretas, nos 8 y 10. 1845, pp. 281-339.

9. Toda la obra de y sobre Musso viene reseñada en José Musso Valiente (José Luis Molina, ed.), Obra, 3 vols., Universidad de Murcia-Ayuntamiento de Lorca, Murcia, 2004, vol. I, pp. 13-68. Se recomienda por los numerosos estudios que la componen, Manuel Martínez ArnaldosJosé Luis Molina Martínez-Santos Campoy García (eds.), José Musso Valiente y su época (17851838) La transición del Neoclasicismo al Romanticismo (Actas de Congreso Internacional "Musso Valiente y su época (1785-1838)", celebrado en Lorca los días 17, 18 y 19 de noviembre de 2004), Universidad de Murcia-Ayuntamiento de Lorca, Murcia, 2006. 
de Sevilla entre 1833 y 1835, su eclosión definitiva se produce entre octubre de 1835 y su óbito, ocurrido el 31 de julio de 1838.

Según el mismo Musso deja escrito en su Memorial de la Vida, conoce a Martín Fernández de Navarrete con ocasión de ser propuesto como correspondiente de la Real Academia de la Historia:

"Como en casa de los condes de Revilla Gigedo conociese al presbítero don José Sabau ${ }^{10}$, editor y comentador del Mariana, este sabio y virtuoso eclesiástico me cobró afición y, siendo individuo de la Academia de la Historia, habló con don Martín Fernández de Navarrete, que también lo era, para introducirme en ella. Navarrete convino sin dificultad y, como yo no tenía residencia fija en Madrid, me propuso para correspondiente. La Academia me nombró por unanimidad de votos y, desde entonces, concurriendo sin faltar a las sesiones que celebra los viernes, tomé parte en sus tareas"11.

A partir de este suceso, José María Musso y Pérez Valiente ${ }^{12}$ entra en contacto con la elite eclesiástica, académica e intelectual del momento, hasta tal punto que, si Navarrete pertenece a las reales Academias de la Historia, Española (de la que fue Director muchos años) y de San Fernando ${ }^{13}$, Musso lo es de

10. José Sabau y Blanco (1757-1833), secretario del Consejo de S. M., arcediano de Aliaga (Zaragoza) y canónigo de San Isidro de Madrid y de Burgos (1818), Secretario de interpretación de lenguas (1830) y obispo electo de Osma (1833). Compuso la nueva edición con adiciones de la Historia de España de El padre Mariana (con este título aparece en la biblioteca de Musso), en 20 tomos, que se publica entre 1817 y 1822. También es autor de La moral de Jesucristo y de los Apóstoles (1834). En la Real Academia de la Historia es supernumerario en 1817, numerario en 1823, para cuyo ingreso lee Memoria sobre la excelencia del estudio de las monedas para la Historia, Anticuario perpetuo (1820) y Bibliotecario perpetuo (1821).

11. Cfr., José Musso Valiente (J. L. Molina Martínez, ed.), Obras, vol. I., cit., p. 467.

12. No se olvide que Musso Valiente es nieto de Pedro José Pérez-Valiente (1713-1789), internacionalista, Consejero de Castilla, humanista poseedor de una biblioteca considerable (vid., Ana Isabel Quintanilla, "La biblioteca de Pedro José Pérez Valiente", en Cuadernos de Historia Moderna 24, 2000, pp. 137-166.

13. Martín Fernández de Navarrete (1765-1844), Capitán de Navío de la Armada Real, Oficial Mayor primero de la Secretaría del Despacho Universal de Marina (1803), académico de la Española (1792), Historia (1800) y San Fernando (1782). Durante su estancia en Cartagena, colabora en el Semanario Literario y Curioso de Cartagena (1786-1788). Su obra más importante es Colección de viajes y descubrimientos que hicieron por mar los españoles desde fines del siglo XV, con varios documentos inéditos convenientes a la historia de la navegación marítima castellana y de los establecimientos españoles en Indias (dos tomos, en 1825, el $3^{\circ}$ en 1829 y $\operatorname{los} 4^{\circ}$ y $5^{\circ}$ en 1837). 
la de Historia, Española ${ }^{14}$, de San Fernando ${ }^{15}$, de Ciencias y Grecolatina (Latina Matritense). Pero, desde la presidencia de la Española y desde una posición inmejorable, junto a Clemencín, Musso en la de la Historia, gestiona, dirige y proyecta una serie importante de investigaciones en las que es parte básica, tanto por sus conocimientos como por su capacidad de trabajo.

"Llegamos de este modo al final de su vida con una obsesión que le preocupa enormemente: el rescate de multitud de documentos trascendentales de nuestros archivos y bibliotecas para crear una auténtica "Historia de España", lo que él Ilamo su Colección de documentos inéditos para cuya realización tuvo como ayudantes a dos antiguos afrancesados y amigos de Moratín, Miguel Salvá ${ }^{16}$ y Pedro Sáinz de Baranda, tan vilipendiados

14. "También a mediados de 1827 me abrió la entrada la Academia Española. Origen de esto fue una conversación con Navarrete, después de la cual me avisó D. Tomás González Carvajal, traductor de los libros poéticos de la Biblia, cuándo debía poner el Memorial. Admitiéronme en clase de honorario, por unanimidad, y al tomar posesión leí un discurso sobre la influencia del carácter de las naciones en la formación de las lenguas y de estas en las que las hablan. Meses después ascendí a supernumerario y, a mediados del 30, a individuo de número" [cfr., José Musso Valiente, "Memorial de la vida", en (J. L. Molina Martínez, ed.), Obras, cit., p. 472].

15. Musso pertenecía ya a las Academias de la Historia, Española y Grecolatina cuando comenzó a redactar, a partir del cuaderno 12, la Colección litográfica de los cuadros del rey que dirigía José de Madrazo. Esto le permitió entrar en la de San Fernando, como él mismo transmite: "La del Museo era muy apreciada y, con este motivo, leyéndose los textos que la acompañaban, oyeron mi nombre personas que ni siquiera sabían existiese. Una de ellas fue el Comisario general de Cruzada don Manuel Fernández Varela, viceprotector de la Academia de San Fernando (1829-1834), que influyó en ella para que me admitiese y realmente me nombró esta en clase de honorario a mediados de 830" [cfr., José Musso Valiente, "Memorial de la vida", en (J. L. Molina Martínez, ed.), Obras, cit., p. 477]. En su Diario hace la siguiente anotación: el día 9 de agosto de 1830: "Real Academia de San Fernando. Noticias domésticas. Con fecha 29 de julio, me oficia Navarrete que la Academia de San Fernando me ha nombrado Académico de honor. Hoy contesto dando gracias." Martín Fernández de Navarrete fue Secretario de esta Academia entre 1815 y 1834. Vicesecretario entre 1827 y 1846 fue Juan Miguel de Inclán Valdés y Conserje entre 1816 y 1844 Juan Manuel Arnedo. Vid., Esperanza Navarrete Martínez, La Academia de Bellas Artes de San Fernando y la pintura en la primera mitad del siglo XIX, Madrid, Fundación Universitaria española, 1999, p. 57. En la página 458 de este mismo libro, aparece Musso como académico de honor, única vez que lo cita, lo que indica que nada debe quedar en el archivo de su paso por San Fernando, pero, entre paréntesis, aparece 1828-1830. Posiblemente en 1828 se propuso a S. M. y se nombró el 1830, pues el nombramiento de los académicos de honor "era real y a propuesta del protector; pero también la Academia podía hacer los que considerara oportunos siempre que fueran apoyados por el mismo protector o viceprotector" (p. 57). Pero si esto fuese así, no fue propuesto por Fernández Varela, cuestión de escasa importancia.

16. Miguel Salvá y Munar (1791-1873), presbítero, vecino de Pamplona en 1830, obispo de Mallorca en 1851, correspondiente en la Junta de 18 de abril de 1829, supernumerario en 1831; su discurso versó sobre la Vida del arzobispo Carranza; numerario en 1836 con un discurso sobre Ilustración a las Cortes de León de 1020 y de Coyanza de 1050 (Vid. Boletín de la Real Academia de la Historia, Tomo CLXXV, Madrid, 1978, p. 94). Según, Cuenca Toribio, J. M., 
por otro importante cervantista, D. Bartolomé José Gallardo, a los que Ilamó con sorna y pícaro discurso "gacetilleros de Bayona", como su amigo y corresponsal José Mor de Fuentes ${ }^{17 "}$.

\section{El Museo de Antigüedades}

Aunque también daré a conocer las relaciones existentes entre ambos derivadas de la situación académica en las diferentes Academias de que tenemos noticia a través de su Diario -estoy convencido de que se podrían aumentar los testimonios buscando entre las actas de las Academias a las que pertenecieron y a los propios papeles de Navarrete-, son dos la situaciones más interesantes que relatar se pueden porque afectan no sólo a las relaciones personales sino a la trascendencia de las decisiones académicas, pues la iniciativa de Musso era muy coherente y quizá fuesen los intereses corporativos los que abortaron la misma.

En todo momento nos servirán de guía los escritos de Musso, básicamente su Diario y su Memorial de la vida.

"Más lisonjeras esperanzas prometía la formación de un Museo de Antigüedades en la Corte, sobre lo cual hablé repetidas veces con Cortina ${ }^{18}$. Veíamos que los monumentos de la antigüedad iban desapareciendo de entre nosotros, o que no cuidando nadie de ellos pronto nos quedaríamos sin ninguno. De ahí deducíamos que si se formase un gabinete donde se recogiesen, se evitaría tal desastre y recibiría por ello gran lustre la nación. Escribí pues el prospecto y ambos lo presentamos a don Juan Miguel de Grijalba ${ }^{19}$, sobrino del marqués de Zambrano, ayuda de cámara de S. M., de quien era muy favorecido, y amante de las artes y las letras. Agradóle mucho, opinó por su buen éxito, y nos exhortó a ponerlo en manos del Rey. A mí, en particular, me dijo que S. M. tenía ya noticia de mí y deseaba conocerme. Con esto, solicitamos audiencia y se nos concedió una noche después de la pública. El rey nos recibió con la mayor bondad; me estuvo preguntando por la edición de Moratín y la colección litográfica, tomó el memorial y lo puso con separación. Remitióse a pocos días, como habíamos pedido, a informe de la Academia de la Historia porque, perteneciendo Cortina y yo a ella, creíamos que el

Sociología del episcopado español e hispanoamericano (1789-1985), Madrid, Pegaso, 1986, p. 512, nace en 1872.

17. Cfr. J. F. Cáseda Teresa, Martín Fernández de Navarrete y la literatura de su tiempo, cit., pp. 33-34.

18. Se trata de José Justo Gómez de la Cortina.

19. Juan Grijalva, miembro de la camarilla, guardasellos de Fernando VII, protagonista de los sucesos de La Granja (1832), desapareció de la vida pública tras la muerte del rey. 
informe sería cual pudiéramos desear; pero completamente la erramos. Navarrete y Clemencín, director y secretario respectivamente, se incomodaron muy mucho, llevando a mal la pretensión nuestra porque, decían, que con ella usurpábamos las facultades de la Academia. Por cierto, no viendo fruto alguno de ella, nos habíamos olvidado de que a su cargo está la Inspección de las antigüedades de España. Si por esto, dieron o no pasos para parar el proyecto, lo ignoro; de ello hicimos conversación los interesados y un amigo me dijo redondamente que no lo pusiese en duda y que a esto debía atribuirse que el plan, no obstante que el informe que se me leyó antes por Clemencín y a mí me pareció bueno, sin que pueda añadir si contenía alguna expresión contraria a él, se frustrase. Lo cierto es que todo paró en una comunicación que a Cortina y a mí se nos pasó, en la cual, elogiando nuestro celo, se añadía que la penuria del erario imposibilitaba entonces la ejecución de lo que solicitábamos ${ }^{20 \prime \prime}$.

Así resume, tan brevemente, este negocio que expone de manera mucho más pormenorizada en su Diario $^{21}$.

\section{9}

Marzo.

Día 13. Real Academia de la Historia. Ha leído el Director el prólogo que ha puesto al tomo $3^{\circ}$ de la Colección de Viajes marítimos de nuestro antiguos navegantes a la América ${ }^{22}$.

Noviembre.

Día 28. Real Academia de la Historia. Noticias domésticas. Habiendo formado un proyecto de museo de antigüedades, le leí a Cortina quien, gustándole mucho, hizo que se pusiese en limpio y, firmado por ambos y por Montenegro, le entregó a D. Juan Grijalva para que le leyese y diese su parecer. Este manifestó haberle agradado y añadió que debíamos presentarlo a S. M. Con esto, se

20. Cfr., José Musso Valiente (J. L. Molina Martínez, ed.), Obras, vol. I., cit., p. 467.

21. El Diario se conserva en el Archivo Municipal de Calasparra (Murcia).

22. "Diario, 10 de junio de 1829. Viajes marítimos de los españoles. Está publicando D. Martín Fernández de Navarrete la colección de los viajes y descubrimientos que hicieron por mar los españoles desde fines del siglo XV, la cual de orden del Rey se imprime en la imprenta real. Van ya tres tomos de los cuales los dos primeros contienen los viajes de Colón y descubrimiento del nuevo mundo. El autor me ha regalado el tercero que comprende los viajes menores y los de Vespucio, las poblaciones en el Darién y un suplemento al tomo II. La obra va comprobando con una gran porción de documentos casi todos inéditos y está exornada con prólogos, notas e ilustraciones no menos curiosas que juicios y críticas de Navarrete, siendo una nueva prueba de la laboriosidad, celo patriótico y fino discernimiento del mismo, y ofreciendo muy ricos materiales para la historia de la América". El Darién es una zona de selva tropical protegida (Reserva de la Biosfera) situada entre Panamá y Colombia que interrumpe el paso de cualquier carretera. La región del Darién, de unos 160 km, funciona como una barrera natural entre América Central y del Sur y sólo puede atravesarse por caminos sin asfaltar. 
volvió a copiar, dirigiendo la palabra a S. M., y, obtenida audiencia por medio del mismo Grijalva, lo hemos presentado al Rey esta noche Cortina y yo. S. M. le ha recibido con mucho agrado, diciendo tenía ya noticia de ello.

1830

Enero

Día 29. Real Academia de la Historia. Navarrete. Ha continuado leyendo la vida de D. Álvaro de Bazán, primer marqués de Santa Cruz.

Febrero

Día 4. Navarrete. Me ha regalado un ejemplar impreso de la Noticia biográfica de D. Álvaro de Bazán, primer marqués de Santa Cruz, escrita por el mismo por encargo del Ministerio de Marina, cuyo ejemplar lleva su firma al fin.

Día 5. Real Academia de la Historia. Navarrete. Ha acabado Navarrete de leer la noticia biográfica de D. Álvaro de Bazán, primer marqués de Santa Cruz.

Día 19. Real Academia de la Historia. Noticias domésticas. Se leyó un oficio del Ministro de Estado en que decía remitir a la Academia para que informase un plan que firmaba yo en primer lugar y después Cortina y Montenegro (D. Antonio) dirigido a S. M. para la ejecución de un museo de antigüedades. Mas, como por equivocación no se había remitido el papel, se suspendió el acuerdo hasta que se recibiese este. Para de más fácil inteligencia de la Academia, acordamos Cortina y yo antes referir a los principales académicos los antecedentes del negocio; como Madrazo había hablado conmigo manifestándome haber tenido D. Juan Grijalba ánimo de formarle en una pieza de palacio; como en el cuarto de este se había renovado la conversación acerca de ello y añadídose el plan de un viaje artístico por la península para levantar planos y sacar vistas de monumentos, haciendo también excavaciones recogido lo que se encontrase, como había añadido yo la idea de que se fundasen cátedras sobre los ramos que abraza este estudio; como se había formado el escrito, que era, en verdad, fruto de estas conversaciones, se había presentado a S. M., después de haberle visto y aprobado Grijalba, y considerando siempre sobre el supuesto de contar con la Academia de la Historia; como, en fin, pasado a la Secretaría de Estado de acuerdo con nosotros, se había remitido a la Academia. Conforme a lo convenido entre Cortina y yo, le referí así al P. Canal, a Clemencín, a González y algún otro, habiendo quedado el mismo en hacerlo presente a Navarrete.

Día 21. Noticias domésticas. Me ha dicho Navarrete que Cortina no le había dicho nada sobre el museo de antigüedades porque, cuando se vieron, había gente delante, pero que ha visto el plan, porque equivocadamente se remitió a la Academia de San Fernando, $\mathrm{se}^{23}$........ devolvieron manifestando la equivocación. Añadió muy incomodado que la Academia no tenía que informar más que 2 palabras, a saber, que, si se llevaba adelante, cesaba esta en sus funciones, pues que la principal era la de formar el museo, que vería reducida a la

23. Palabras ilegibles en el original. 
nulidad como sucedería con la Academia Española si a los maestros de primeras letras se diese la comisión de formar el diccionario y la gramática de la lengua, y que nosotros habíamos procedido mal en no haber contado con la Academia para formar nuestro papel. He procurado desvanecer tan extrañas suposiciones demostrando que ni era obligación nuestra pedir permiso ni consultar a la Academia para proponer a S. M. o quien tuviésemos por conveniente, ni habíamos pensado menoscabar en la más mínimo las facultades de la Academia. He referido después el lance a Madrazo que me ha dicho podía llamarse el proyecto propio de Grijalba que muchas veces había hablado de él, que convendría decir a este lo ocurrido y que todo era equivocación de Navarrete.

Día 22. Noticias domésticas. He referido el lance de Navarrete sobre el museo de antigüedades al P. Canal, a Clemencín y a Olive ${ }^{24}$ como compañeros de Academia. $Y$ han convenido en decir que Navarrete procede equivocadamente y que el proyecto merece elogios y no vituperios. También he conferenciado con Cortina sobre el particular y hemos quedado acordes en los pasos que debemos dar acerca de ello.

Día 23. Noticias domésticas. He hablado con Sabau sobre el museo de antigüedades, le he referido los antecedentes del negocio y el lance de Navarrete. El proyecto le ha parecido muy bien y la oposición de Navarrete muy mal, pues la considera enteramente infundada.

Día 25. Noticias domésticas. Me ha dicho Cortina que ha hablado con Navarrete sobre el museo de antigüedades y que no se muestra ya tan contrario a él. Dio este por supuesto que no se pensaba en privar a la Academia de sus facultades, ni de lo que posea en este ramo, y Cortina se lo confirmó. Después hemos ido a ver a Grijalba, a quien hicimos presente haberse pedido informe a la Academia de la Historia, que regularmente se daría cuenta en ella mañana, y que se presentaba aspecto favorable. Y respondió que así lo creía pues no había motivo para que se mostrase contraria.

Día 26. Real Academia de la Historia. Noticias domésticas. Se ha vuelto a leer la orden del Gobierno relativa a la erección del museo de antigüedades propuesto por Montenegro y Cortina unidos conmigo. Y se ha acordado que la examine e informe Clemencín y el P. Canal. Estos, concluida la sesión, me han dicho que concurra con ellos el lunes a tratar del negocio.

\section{Marzo}

Día 1. Real Academia de la Historia. Noticias domésticas. Reunida la comisión nombrada para informar sobre el proyecto del Museo de Antigüedades y estando

24. Pedro María Olive, periodista (El Memorial Literario o Biblioteca Periódica de Ciencias y Artes (1801-1804), La Minerva (1805-1808), La Minerva o el Revisor General, 1817-1818, periódico en el que aparecen las primeras poesías y traducciones de Musso), autor de Nuevas efemérides de España, históricas y literarias (1805), Consideraciones sobre el engrandecimiento, decadencia y restablecimiento de la casa real de los Borbones (1826) y Diccionario de sinónimos de la lengua castellana (1843). Era el redactor de la gaceta que se imprimía para el ejército que mandaba Musso en la guerra de la Independencia. 
yo presente, se leyó el oficio del ministro y el proyecto. A los 5 días de la fecha de este se hallaba el decreto: Al extracto y dése cuenta sin ponerse en lista. Apenas se acabó la lectura, tanto Clemencín como el P. Canal repitieron contra el escrito las mismas objeciones que Navarrete, y el segundo, como más franco, no tuvo reparos en confesar que el día anterior había estado con éste y habían hablado del proyecto, y añadió que las 3/4 partes de los académicos le miraban como un ataque al cuerpo. Procuré desvanecer las objeciones; obstináronse más en su opinión. Al ejemplo de otras Academias y museos extranjeros, respondía Clemencín, que aquellas no tenían las facultades de esta. A la réplica de que ésta con toda esa bulla hacía un papel muy ridículo pues en un siglo no había dado un paso para la formación del museo, había perdido lo más precioso de su monetario y bajo su inspección habían aparecido muchísimos monumentos antiguos, destruidos unos, vendidos otros a los extranjeros, en fin, en el día ignoraba el estado de la antigüedad de toda la península, respondió que no tenía medios ni edificio. A la instancia de que habiéndole preguntado el Gobierno dos veces cuáles serían los mejores medios para preservar de su destrucción las antigüedades que nos quedaban, nunca se había acordado de pedir ni edificio ni dinero; contestaba que nuestro escrito atacaba a la Academia pues por eso mismo que yo decía la acusábamos. Otras muchas demandas y respuestas pasaron que ni acaso es decoroso referir. Concluyó Clemencín diciendo que debían informar no había sobre ello que tomar providencia pues era del instituto de la Academia; mas como dijese yo entonces que nosotros también hablaríamos claro, me contestó que era menester evitar un rompimiento y que procediésemos como buenos amigos. A lo que repuse que tal era mi deseo. En fin, propuse que informasen se dijese a S. M. que la Academia se oponía a la formación y aumento del Museo pero que ella se encargaría de formar uno público con las antigüedades que recogiese de la península y tomaría a su cargo la erección de cátedras. Esto agradó a Canal, pero Clemencín dijo que se meditase y que volviéramos a tratar del asunto pasado mañana. Luego vi a Cortina y después a Olive. A ambos conté la sesión y se admiraron de tan impertinente resistencia. Les insinué que me ocurría la especie de proponer a S. M. que sus antigüedades y las demás que fuese adquiriendo se reuniesen en el Museo del Prado bajo la dirección del mismo Duque de Híjar que está al frente de él. Y les pareció bien y convinimos en que mañana hablaría con Madrazo acerca de ello ${ }^{25}$.

Día 2. Real Academia de la Historia. Noticias domésticas. He referido a Madrazo lo ocurrido ayer y le ha incomodado la oposición de la Academia. El mismo me ha dicho que había contado a Grijalba mi sesión con Navarrete y que le había concertado que la salida de este era una extravagancia. Ha convenido en que se pasen las antigüedades del Rey al Museo del Prado y añade que se debe proponer a S. M. estén a cargo de una persona inteligente bajo las órdenes de Híjar. Enseguida he hablado con éste y ha dicho que aras, candelabros, capiteles, etc.,

25. José de Madrazo y Agudo (1781-1859), pintor de Cámara (1816), profesor de la academia (1829), director del Museo del Prado (1838), amigo personal de Musso. 
pertenecen a la escultura y, desde luego, sin nueva orden se agregarán, y que lo demás me parece bien que se proponga a $\mathrm{S}$. M. para que se coloque en piezas separadas. Lo he referido todo a Cortina y hemos quedado en que mañana hablaré a Grijalba del particular.

Día 3. Real Academia de la Historia. Noticias domésticas. Habiendo hecho al P. Canal varias reflexiones sobre la propuesta que hice anteayer acerca del Museo de Antigüedades, mostró haberse convencido y dijo que la propuesta le parecía juiciosa. Llegó después Clemencín y, como se desentendiese del asunto, el P. Canal le Ilamó la atención sobre él. Entonces Clemencín hizo más viva oposición que la vez anterior, sin convencerse por ninguna reflexión y mezclando argumentos políticos en que propaló opiniones que no venían a propósito ni eran oportunas. Concluyó diciendo que todo lo que no fuese estorbar de todos modos que el Rey formase nuevo Museo, era negocio perdido. No pude menos de oponerme con vigor a tal desatino y Clemencín, incomodado, dijo que el viernes próximo se excusaría de la comisión. Conté el lance a Olive que convino en mi modo de pensar. Lo mismo Madrazo, a quien después se lo insinué. Ambos manifestaron que era necesario dar cuenta a Grijalva.

Día 4. Real Academia de la Historia. Noticias domésticas. He referido a Cortina, a Sabau y a Madrazo lo ocurrido ayer en la sesión sobre el museo de antigüedades con Clemencín y lo han extrañado mucho, Ilevando muy a mal la oposición de éste. Hemos convenido los autores del proyecto en desistir de él, sin tener ya intervención alguna en cuanto la Comisión o la Academia traten acerca de este punto, reservándonos el derecho de acudir a S. M., si fuese necesario, para que no padezca nuestro honor y reputación.

Día 5. Real Academia de la Historia. Noticias domésticas. Estando en la celda del P. Canal, me dijo éste que Clemencín había quedado en Ilevar el borrador del informe sobre el museo de antigüedades en los términos que los 3 habíamos convenido, o, por mejor decir, que yo había propuesto. Con este motivo he esforzado mis razones y el P. Canal ha mostrado estar plenamente convencido. A poco vino Clemencín y, antes de leer el informe, dijo que convenía ir prevenidos, pues ciertamente algunos creían que la Academia tenía motivos para sentirse por el proyecto y que sería necesario, si algo decían, imponerles silencio. Después de esto leyó el informe que abrazaba 2 partes, $1^{\text {a }}$ el proyecto y $2^{\text {a }}$ los medios. En cuanto a lo primero, haciendo el análisis de él, le alababan en extremo, y, en cuanto a lo $2^{\circ}$, dejando S. M. elegir los medios que tuviese por conducentes, exponía la Academia cuanto la misma había trabajado en el particular y cómo por falta de sitio y por la escasez de fondos no había hecho más. Yo dije que me parecía conveniente que pidiese formalmente sitio y fondos, mas replicaron que no convenía. De esto di cuenta a Sabau, a Olive y a Cortina, que se alegraron tanto cuanto habían sentido las anteriores ocurrencias. Y el último me dijo que ayer estuvo con Clemencín y le habló al alma sobre el negocio, quejándose del agravio que se nos hacía y que al fin le dejó persuadido de la razón con que procedíamos. Esta tarde se ha leído el informe en la Academia. González le alabó y dijo se conformaba con él en todas sus partes. Y la Academia entera lo aprobó, acordándose que se nos diesen las gracias por el pensamiento. Cortina respondió por sí y por los otros dos que con él habíamos firmado el proyecto, mostrando nuestro reconocimiento al cuerpo por el honor que nos dispensaba. 
Día 6. Real Academia de la Historia. Noticias domésticas. He dicho al P. Canal y a Clemencín los paso extrajudiciales que pensaba dar para que, sin perjuicio de que S. M. formase el Museo de Antigüedades, lograse la Academia los medios necesarios para formar uno copioso, quedando también a su cargo la erección de cátedras. Con anuencia de ambos, he visto a D. Juan Grijalva y explicádole mis ideas sobre ello. No le ha parecido mal ni tampoco el que se amplíen en un nuevo decreto que se una al expediente. Lo he referido todo a Madrazo, excepto esta última circunstancia, y le ha parecido bien.

Día 8. Real Academia de la Historia. Noticias domésticas. He referido al P. Canal y a Clemencín en sustancia lo que hablé ante ayer con Grijalva sobre el Museo de Antigüedades y les ha parecido muy bien.

Día 18. Real Academia de la Historia. Noticias domésticas. Conforme a lo acordado, Grijalva ${ }^{26}$ ha extendido un papel dirigido a S. M. en que propongo los medios de llevar a efecto el plan del Museo de Antigüedades. Le han leído Navarrete y Canal y les ha parecido bien. Después le llevé a Cortina quién juzgó se debía modificar. Sobre ello se quedó con él y hoy hemos convenido en que el día 20 por la noche nos juntaremos y los corregiremos.

Día 26. Real Academia de la Historia. Noticias domésticas. He presentado las capillas de varios pliegos del primer tomo de Moratín y han gustado mucho, y la Academia ha acordado que se nos den las gracias a los encargados de la edición, lo que en su nombre ha hecho el Director, Navarrete, particularizándose conmigo de un modo muy expresivo y exhortándome a despreciar habliIlas de gentes inconsideradas, supuesto que la Academia estaba muy satisfecha de mi celo. He hecho presente que el pintor de cámara D. José de Madrazo no quería nada por el dibujo del Hamlet y ha acordado la Academia que se le den las gracias por escrito.

Mayo

Día 7. Real Academia de la Historia. Noticias domésticas. El ministro de Estado Salmón ${ }^{27}$ ha remitido una real orden por la que S. M. se ha servido declarar que tomará en consideración para cuando haya proposición y medios lo informado por la Academia sobre el proyecto de Museo de Antigüedades que Cortina, Montenegro y yo propusimos.

Día 21. Real Academia de la Historia. Noticias domésticas. He leído la noticia sobre la vida y escritos de Moratín que he escrito recogiendo los materiales de un cuaderno muy abultado que ha enviado Silvela y que después he corregido de acuerdo con Quintana. La Academia se ha mostrado muy cumplida y ha acordado se imprima al frente de la edición de sus obras. Por advertencia de algunos señores, se han hecho 2 ó 3 ligerísimas correcciones. Después de la sesión he dado el manuscrito a Clemencín para que también le corrija y encargado la remita luego para lo mismo a Navarrete. El mismo Clemencín ha leído

26. Juan Miguel Grijalva, miembro de la camarilla, guardasellos de Fernando VII, uno de los protagonistas de los sucesos de La Granja de 1832.

27. Manuel González Salmón (?-1832), ministro de Estado desde 1826. 
el prólogo a dicha edición, el cual se ha aprobado. Se ha acordado también que la edición se distribuya en 6 tomos como ha propuesto Clemencín y que se le añadan 2 estampas, dándoseme la comisión de elegir asuntos y profesores que los dibujen y litografíen.

Junio

Día 28. Noticias domésticas. He estado a despedirme Navarrete. Este me dijo que pronto volvería, pues ya procuraría que se me diese cosa con la cual pudiera aquí sostenerme, que se me nombraría director de un museo de antigüedades. Contesté que no pensaba en ello, ni en volver, y que, en cuanto al museo, en los pasos que había dado, Ilevaba el objeto de que la Academia de la Historia tuviese ese mayor lustre. Replicó que si la Academia lograba casa, tendría que formarle y valerse de persona a propósito, añadiendo que ninguno podría suplir mi falta. Y como en esto hubiese respondido que yo no lo hacía ni para eso ni para nada y que en la Academia había personas de quien echar mano, más capaces que yo de desempeñar el cargo, insistió en lo mismo que antes. Todo esto no es más que un cumplimiento cortesano con sus ribetes de pulla.

Como se nota por esta última expresión, la resolución de este asunto, el modo de enfocarlo y la incorrecta percepción de sus fines molestaron sobremanera a Musso. Pero jamás guardó rencor a nadie.

\section{Las cosas como se escribieron oficialmente}

Estamos convencidos de que, entre la versión que Musso narra en su Diario y lo que oficialmente se conserva en la misma Real Academia de la Historia, hay una pugna de intereses, de celos, de malas interpretaciones y de zancadiIlas. Por ello, hemos preferido publicar tal cual la versión Musso. Ahora exponemos, aunque sea con una larga cita, otra versión diferente ${ }^{28}$, al menos, más oficial.

"Pero sin lugar a dudas el hecho más destacado de este periodo lo constituye la iniciativa de crear un Museo Español de Antigüedades, una cuestión de indudable importancia, aunque hasta hoy prácticamente desconocida, ya que constituye el precedente directo de la creación del Museo Arqueológico Nacional, y que recientemente hemos expuesto con mayor amplitud y detalle en otro lugar $^{29}$. Aunque el origen de esta idea se remonta a 1803, el proyecto no tomó cuerpo hasta principios del año de 1830, en el que Manuel González Salmón,

28. Vid., Jorge Maier Allende, "La comisión de Antigüedades de la Real Academia de la Historia", en Martín Almagro Gorbea y Jorge Maier Allende (eds.), cit., pp. 25-51.

29. M. Almagro-Gorbea y J. Maier, "El futuro desde el pasado: la Real Academia de la Historia y el origen y funciones del Museo Arqueológico Nacional", cit., p. 183-207. 
Secretario de Estado de Fernando VII, remite de Real Orden a la Real Academia de la Historia para que informe sobre una exposición de José Musso, José Gómez de la Cortina y Antonio Montenegro en la que proponen se forme por separado y absolutamente independiente de todos los demás establecimientos un Museo de Antigüedades en el que se conserven los tesoros que de este género posee la España ${ }^{30}$.

En realidad, se trata de una iniciativa que partía de la Real Academia de la Historia ya que tanto José Musso como José Gómez de la Cortina eran académicos supernumerarios y muy vinculados a este Cuerpo Literario, sobre todo el primero de ellos, como se refleja en las Actas correspondientes a estos años ${ }^{31}$.

Aunque no hemos tenido oportunidad de consultar la referida exposición sí conocemos el espíritu del proyecto por el informe remitido por la Real Academia de la Historia a Manuel González Salmón, en el que se exponen ideas muy modernas respecto al carácter que habría de tener dicho Museo Español de Antigüedades. En efecto, la idea original expuesta por Musso, Gómez de la Cortina y Montenegro es que sería conveniente formar un Museo de Antigüedades en que además de recogerse y coordinarse las preciosidades que ya posee en diversos parages y adquiriese en lo sucesivo S. M. se formase una biblioteca escogida del mismo asunto, y se estableciesen enseñanzas de geografía antigua, inscripciones, numismática y demás asuntos pertinentes a Antigüedades. La idea era crear, por tanto, un Museo que contenga las colecciones de antigüedades de propiedad real además de las que posee la Real Academia de la Historia.

30. Oficio de Manuel González Salmón al Secretario de la Real Academia de la Historia, Palacio, 15 de enero de 1830, CAM/9/7961/7(3).

31. José Musso y Valiente (1785-1838) era académico correspondiente desde el 13 de marzo de 1825, supernumerario desde el 8 de junio de 1827 y fue nombrado académico numerario el 19 de diciembre de 1837. Era además académico numerario de la Real Academia Española y de la de Nobles Artes de San Fernando. José Gómez de la Cortina, primogénito del Conde de la Cortina y traductor junto con Nicolás Ugalde de la Historia de la Literatura Española de Friedrich Bouterweck, fue nombrado supernumerario el 13 de febrero de 1829; posteriormente pasó a la categoría de académico honorario en Méjico a donde regresó, pues de allí era natural. Musso y Gómez de la Cortina fueron encargados por Fernando VII de dirigir la edición de las obras completas de Leandro Fernández de Moratín, que publicó la Real Academia de la Historia. Pero según dice Ramón de Mesonero Romanos en sus Memorias de un Setentón (1994, 377-380), entre 1827 y 1828 se reunían, los domingos por la mañana, en casa de José Gómez de la Cortina... los jóvenes dados por irresistible vocación a conferir con las musas o a ensuciarnos las manos revolviendo códices y mamotretos, ocupaciones ambas que, atendidos los vientos reinantes a la sazón, tenían más de insensatos que de racionales y especuladoras; entre los que asistían a esta tertulia cita a Nicolás Ugalde y Mollinedo, José Musso y Valiente, Manuel Bretón de los Herreros, Antonio Gil y Zárate, Rafael Húmara y Salamanca, José del Castillo y Ayensa, Patricio de la Escosura, Mariano José de Larra, Manuel de San Pelayo, Enrique de Vedía, Serafín Estébanez Calderón, Ventura de la Vega y Antonio María Segovia e Izquierdo. Resulta irresistible pensar que fue en esta reunión dónde surgió la idea de crear el Museo Español de Antigüedades. 
Pero lo más reseñable es que la intención no era tanto la de crear un Museo con una función meramente expositiva, sino que se concibió con un contenido mucho más amplio, desarrollando la investigación y la enseñanza a través de la creación de cátedras que abrazaban todos los ramos de las Antigüedades con el apoyo de una biblioteca especializada. Por otra parte, no menos importante es la idea de su carácter "Español", es decir, Nacional tal como subyace en el proyecto, lo que supone no tanto un concepto político, como hoy tiende a entenderse, sino relacionado con su función de contribuir a la cultura de toda la Nación ${ }^{32}$.

La Academia contesta a través de su Secretario Diego Clemencín en una larga exposición el 6 de marzo de $1830^{33}$ :

Nada hai en concepto en la Academia mas digno de la atención de S. M. que la formación de un Museo, donde se recojan y custodien los monumentos de la venerable Antigüedad, preservandolos de las injurias del tiempo, del descuido y de la ignorancia. Establecido el Museo que se propone de un modo decoroso, sería uno de los adornos de la Corte, en que los extrangeros que lo visitasen verian las muestras de la cultura de la Nación y de la sabiduría de su Gobierno. Al mismo tiempo el público español tendría a la vista una colección de objetos dignos de su curiosidad y estudio, promoviendose de esta suerte la aficion a esta clase de conocimientos que florecen en los demas pueblos de Europa y señaladamente en Italia: conocimientos en que tanto se distinguieron D. Antonio Agustín y Ambrosio de Morales y otros de nuestros antiguos sabios, y que en el dia se hallan desatendidos y atrasados entre nosotros. Seria todavia mas recomendable este Museo, si como se pide en el proyecto a S. M., se le agregase una biblioteca completa de este ramo, en que las personas aficionadas pudiesen hallar los muchos, raros y costosos libros que tratan de la materia, y, en ellos una copiosa mina de noticias y muy para su instrucción. Y si se añadiesen escuelas en que se enseñasen metodicamente los conocimientos relativos a las Antigüedades entonces nada habría que desear para la perfección de su establecimiento tan util y aun tan necesario ya en el estado actual de la ilustración europea. Por lo tanto opina la Academia que el pensamiento es sumamente plausible, y que merece elogios del celo de los que le han presentado a S. M. ${ }^{34}$.

En definitiva, la idea fue totalmente asumida por la Real Academia de la Historia. Pero la situación del Real Tesoro en este momento, como la dificultad

32. Cfr., M. Almagro y J. Maier, cit., 1999.

33. El informe presentado a la Academia por la Sala de Antigüedades fue elaborado por José de la Canal y el propio Clemencín. CAM/9/7961/7(5).

34. Oficio de Diego Clemencín a Manuel González Salmón, 6 de marzo de 1830, CAM/9/7961/7(6). 
para encontrar un edificio proporcionado a este objeto, que a la larga constituyó uno de los inconvenientes más importantes de solventar, dejaron en suspenso el proyecto. No por ello se doblegó la Real Academia de la Historia ante estos obstáculos sino que continuó tenazmente insistiendo en distintos momentos, hasta que pudo ver con satisfacción culminados sus deseos con la creación definitiva del Museo Arqueológico Nacional, en 1867.

Muso sale para Lorca el 30 de junio de 1830, a causa de la situación de la hacienda familiar y, sobre todo, de la vejez de su madre que precisaba su ayuda y que falleció el 31 de marzo de 1833. En esta ciudad se ocupa de la educación de sus hijos, de intentar sacar a flote su economía, de escribir acerca de los riegos de Lorca, de traducir del griego y del latín, y de realizar las comisiones que se había traído de las Academias: definiciones de determinadas palabras para la $7^{\mathrm{a}}$ edición del diccionario, para la Española ${ }^{35}$ y el estudio de la Crónica de Fernando IV para la de la Historia. Nunca concluirá la segunda, aunque la dejó muy avanzada, y sí la primera.

Por ello, la serie de cartas, seis, que Fernández de Navarrete le escribe porque todos esperaban que su regreso fuese algo más anticipado de lo que en realidad fue. Claro que, en medio, se cruza un destino político. Es decir, un medio de ingresar algún dinero para evitar la ruina que pesaba sobre él y los Musso.

Agosto

Día 8. Real Academia de la Historia. En carta de Miñano de 23 de julio sobre la edición de Moratín. En otra de Navarrete de 27 sobre la impresión del tomo $7^{\circ}$ de Memorias.

"Madrid 27 de julio de 1830. Mi estimadísimo amigo: Ya quedo persuadido de que por ahora está usted en la ciudad del Sol. El P. Morote debió haber vivido con los indios del Perú según su afición a aquel astro. También hace de las suyas por aquí, pues estamos estos día a 31 y $32^{\circ}$, con un ambiente sudorífico. Lo que importa es que haya salud en esa familia y que usted vaya componiendo y arreglando sus negocios domésticos para volver aquí como lo deseamos y yo más que todos. Los amigos y compañeros de la Academia agradecieron las expresiones de usted y Escario me informó a su tiempo de haber visto a usted a su paso por Murcia. Clemencín está en su Tusculano por pocos días. Murió D. José Luis Munárriz; va concluyéndose de imprimir el elogio de Arias Montano; Cortina escribirá a Vm. sobre lo de Moratín. Nada más ocurre. Mis chicas saludan a esas damas con cariñoso afecto y yo también deseando a todas con el amo de casa la felicidad y salud

35. Vid., José Luis Molina Martínez, "José Musso Valiente en la Real Academia Española según su Diario (1829-1837). Su intervención en el Diccionario y en la Gramática de la lengua castellana", en Boletín de la Real Academia Española, tomo LXXXI, cuaderno CCLXXXIII, 2002, pp. 255-320. 
que yo para mí deseo como escriben los tíos de los lugares. En todos y en todos tiempos aprecia y apreciará a usted sinceramente su mejor amigo que su mano besa. Martín Fernández de Navarrete ${ }^{36 \prime}$.

Día 9. Real Academia de San Fernando. Noticias domésticas. Con fecha 29 de julio, me oficia Navarrete que la Academia de San Fernando me ha nombrado Académico de honor. Hoy contesto dando gracias.

Diciembre.

Día 1. Real Academia Española. Noticias domésticas. Sobre el Diccionario de la lengua. V. lo que dice Navarrete en carta fecha en Madrid a 26 del anterior

"Madrid 26 de noviembre de 1830. Mi muy estimado amigo: Impensadamente tuve que ir a la Rioja en este verano a la testamentaría de mi hermano mayor, cuando recibí la última de usted con otra para Clemencín que entonces se hallaba en el campo, pero así en mi país como aquí a mi regreso he tenido siempre el gusto de tener noticias de usted y de su apreciable familia. Yo lo he celebrado, y si con la Demetria en Ábalos hablábamos de todas esas damas, procurando yo satisfacer las preguntas que de todas me hacía, aquí por mis chicas y anoche por su hermano de usted he tenido noticias más recientes. Yo hice felizmente mi expedición, pero ya empiezo a sentir el efecto desagradable de los fríos.

Vamos a nuestros asuntos académicos. Ya el Sr. D. Francisco Antonio González me ha dicho que escribirá a Vm. largamente sobre el Diccionario de la lengua y su impresión que si no se ha empezado se empezará uno de estos días. Así que yo de acuerdo con dicho señor, que como usted sabe es tesorero de la Real Academia de la Historia, voy a preguntar a usted de otro asunto. Ya se entregó a S. M. el primer tomo de las Obras de Moratín (en dos volúmenes) y ha quedado muy contento y quiere que se active la conclusión de los demás. Con este motivo y el de pedir más dinero ha querido el Sr. Tesorero arreglar las cuentas de lo que hasta ahora ha librado el Sr. D. Juan Miguel Grijalva y tiene todos los documentos de la inversión de los 50000 reales que se han librado en dos partidas, una de 20000 y otra de 30000; pero faltan los documentos o recibos de los primeros 8000 reales que se tomaron e invirtieron Miñano y usted.

Sabau se acuerda que cuando estaba yo en la Rioja el año pasado de 1829 y presidía la Academia, le presentó usted para firmar una carta o pedido para el Sr. Grijalva de dichos 8000 reales, y yo oí hablar a ustedes después de haber pagado con ellos las primeras entregas del papel a Serra y a algunos dibujantes y litógrafos las primeras láminas. Lo que ahora falta son estos recibos y documentos para justificar la inversión de estos 8000 reales,

36. Carta, como las siguientes, conservada en la Biblioteca-Archivo de la Caja de Ahorros del Mediterráneo en Mula (Murcia), Donación Sánchez Maurandi. 
y así queremos que usted nos diga si están en su poder o a quién los entregaron ustedes, o cuál es su paradero, pues usted sabe que se acordó en la Academia que nada se pagase sin el visto bueno de los comisionados. Lo que nos conviene es tener y reunir dichos documentos y satisfacer al Rey N. Sr. en la legítima inversión de los caudales que tan generosamente nos ha facilitado. Esto procure usted decírmelo con exactitud para satisfacer a la Academia y al Sr. González.

Impresas ya tres Memorias del tomo $7^{\circ}$, ha parado la impresión porque Siles no acaba de despachar su Disertación sobre la introducción del Monacato en España. Y entretanto vamos a ingerir la de D. Tomás González sobre las relaciones políticas de Felipe II con la Reina Isabel de Inglaterra sacada de los documentos originales del archivo de Simancas.

Bien conozco que con el Diccionario, con Fernando $4^{\circ}$ y su madre, con las descripciones de las estampas del Museo, etc., no faltarán a usted ocupaciones en su retiro, pero mi interés es que cuide de su salud y la conserve para volver a vernos aquí y darle pruebas del sincero afecto y fina amistad con que es suyo Martín Fernández de Navarrete. P. D. Ofrézcame usted a los pies de esas señoras con expresiones de mis hijas".

1831

Febrero.

Día 13. Navarrete. Está bastante mal de su habitual que de cuando en cuando le hace arrojar sangre por la boca. V. la mencionada carta de Valle ${ }^{37}$ y otra de Clemencín, fecha en Madrid también a 8.

Agosto

Día 14. Correspondencia con la Real Academia de la Historia. Sobre carta que escribí a Navarrete y acuerdo para que se manden el tomo $V$ de Documentos de las provincias bascongadas y el censo español del siglo XVI, v. carta de Clemencín fecha en Madrid a 9.

Navarrete le escribió, en contestación, desde Madrid una tercera carta de las conservadas, con fecha 30 de agosto de 1831.

"Mi estimado amigo y compañero: ¿Si me dejarán hoy contestar a su apreciable carta del 31 de julio? Porque, ha de saber usted que, sobre las ocupaciones ordinarias que usted conoce, me hallo próximo a las Juntas generales de adjudicaciones de premios y a la pública de su distribución en la Academia de San Fernando y en redactar sus actas de 23 años, que es el periodo que ha mediado desde los últimos premios que, según sus estatutos y prácticas desde su fundación han sido y debido ser cada tres años. Hasta los muertos en tan largo tiempo me ocupan mucho, porque,

37. Esta carta de Eusebio María del Valle no se encuentra en BACAM. 
aunque para la mayor parte basta para su memoria la partida de finado en su parroquia, ¿cómo no hacer excepción de los consiliarios y académicos de honor Jovellanos, D. Pedro de Silva, Ceán, Ortiz y Sanz, de los pintores Maella, Goya, de los escultores Adán, Bergaz, Álvarez, Ginés, de los arquitectos D. Silvestre Pérez, D. Manuel Martín Rodríguez y el célebre Villanueva, de los grabadores Carmona, Selma, Enguidanos (de láminas) y de medallas Gil y Sepúlvedas? Así hay algunos otros. Como el Vice-Protector (Varela) está en el sitio $^{38}$ parece aguardar celebrar esta función cuando la Corte esté aquí.

Entretanto se acerca el término de mi Dirección histórica para el último de noviembre y tengo que disponer mi testamento académico. Ya habrá usted visto por la Gaceta que también hemos ofrecido premios por la primera vez, sin embargo de ser un precepto de estatuto; y ya en Diciembre concurrirán los de Poesía y elocuencia a esta calle de Valverde como las moscas a la miel. ¡Lástima que usted no se halle aquí en esta temporada! ¡Cuánto le deseamos sus amigos! Pero, entretanto, sepa usted que el Diccionario va por la porta; ya están en la $\mathrm{P}$, y dudo que alcancen los artículos de Ciencias Naturales. Pero, con esto al Sr. González. Lo que más nos importa de los encargos que usted tiene es la Crónica de Fernando IV y ver si pueden aprovecharse las 500 páginas del Apéndice e ilustrar con sus documentos por medio de notas la narración de la Crónica, rectificando sus hechos y cronología. ¿Qué de cosas hallará usted para su Reina Doña María? Encargo a usted me dé para Octubre o principios de Noviembre una razón circunstanciada del estado en que lleva este trabajo para hacer mención en mi discurso directorial y enterar al cuerpo y a mi sucesor del adelanto de las obras que se traen entre manos o de su detención o atraso para que pueda darlas el impulso conveniente ahora que no puede dejarse esto por falta de fondos. De los textos litográficos ya veo lo que viene y aun el amigo Madrazo me suele traer las cartas de usted para arreglar las correcciones a lo mismo que usted propone. Así se hizo en el último, pero de lo que usted me dice del Papa y de su prisión por Carlos V, confieso que no me acuerdo haberlo suprimido y acaso fue tachado en el Juzgado de Imprentas después de la censura.

Estuvo Pepito ${ }^{39}$ (que es un excelente muchacho) y, después de habernos entretenido en ver varias poesías manuscritas, se llevó el tomito de las de Jovellanos para copiar las que no están impresas. Lo mismo hará con las de Meléndez, Iglesias, Forner, Yriarte, Samaniego, etc., y así completará usted una buena colección para entretener los ratos ociosos que no serán muchos según su genio y aplicación.

38. Seguramente, por la fecha, se puede suponer que este real sitio sería El Escorial, aunque también podría ser La Granja o Aranjuez.

39. Se refiere a su hijo José Muso y Fontes (1812-1886). 
En la Panadería y en la calle de Valverde todos se acuerdan de usted y le dan finas expresiones y también mis hijas con el aditamento de la mi Señora Doña Concepción, a cuyos pies ofrezco mis respetos, quedando siempre se usted sus fino y apasionado amigo que le aprecia sinceramente. Martín Fernández de Navarrete.

P. D. Acaba Pepito de enviarme el tomito manuscrito de las poesías de Jovellanos. Naturalmente volverá por otras. Entregué a Pepito dos folletos míos para usted y hablé a Banqueri quien quedó en enviar a Clemencín el tomo $V$ de la colección de documentos de Simancas. Algunos hallará usted de Fernando IV".

Septiembre

Día 15. Correspondencia con la Real Academia de la Historia. En este día escribo a Navarrete dando gracias por el tomo $V$ de documentos de Simancas y por el censo español del siglo XVI y digo lo que me ocurre acerca de la crónica de Fernando IV. Sobre uno y otro escribí también el correo último a Clemencín.

Octubre

Día 30. Correspondencia con la Real Academia de la Historia. Por este correo envío a Navarrete una exposición de lo trabajado hasta el 25 del corriente en la comisión de la Crónica de Fernando IV.

Las anotaciones que Musso hacen en su Diario en los años siguientes siguen siendo a través de correspondencia. Más importantes son las de los años 1836 y 1837.

"Madrid, 15 de enero de 1833. Mi estimado amigo y compañero: con mi ocupaciones diarias y con contestar a cuanto preguntan de la nueva Secretaría de Fomento General que se va estableciendo, y con un tiempo tan frío para los que ya le tenemos con los años, he retardado más de lo que quisiera a su apreciable carta de 10 de diciembre. Hágolo ahora para asegurar a usted que mis deseos siempre han estado acordes con los de usted para la admisión de D. Pedro María de Olive en nuestra Academia Española, porque es sujeto que hace tiempo pareció por su ilustración y buen carácter y le veo unido con usted por iguales consideraciones de amistad y dedicado a cultivar nuestro idioma como lo acredita con sus Análisis de las obras de Fray Luis de Granada, que tengo a la vista. Hablé de ello apoyado con el voto de usted a los señores D. Francisco Antonio González y D. Diego Clemencín, y me dijeron que podría diferirse hasta que salgamos de la adjudicación de los premios de Poesía y elocuencia y que entonces podría prepararse el asunto porque hay otros compañeros de la Panadería (D. Marcial López) que le había manifestado iguales deseos. Después ha recaído de sus tercianas el Sr. González de que estado gravemente malo y todavía no asiste a ninguna de las Academias, y usted ya sabe cuánto es su influjo y opinión especialmente en esta. Yo, por mi parte, no dejaré de 
repetir mis recuerdos ni de la mano un negocio que me sería satisfactorio su buen éxito y estoy persuadido sería también conveniente a la Academia. Las poesías manuscritas están siempre a la disposición de usted, pero no veo tiempo a Pepito que andará ocupado estos días, y a su hermano de usted también hace tiempo no le veo por las horas que nos ocupan nuestras obligaciones y ahora por el rigor de la estación para andar de noche por esas calles sucias y excusadas ${ }^{40}$.

He sabido puntualmente todos los disgustos que ha tenido usted en su familia durante el año último y hemos hablado de ello con el interés que usted puede imaginar, ya con mis chicas relativamente al padecer de Encarnación ${ }^{41}$ y de sus padres, ya con otros amigos contrayéndonos a usted en particular. Deseo que este año sea más próspero y feliz en esa mi amada casa y que tenga usted la tranquilidad de ánimo necesaria para entretenerse con el arreglo de la Crónica de Fernando IV y con la Gramática Castellana para la cual, no sé si entre los mamotretos y libros que le enviaron, fue la Gramática que D. Vicente Salvá ha publicado en París, de los cual informó verbalmente a la Academia con aprecio nuestro Clemencín en la última Junta.

Ofrezca usted mis respetuosos afectos a los pies de mi Señora Doña Concepción y sus hija, y cuyo completo alivio deseo; y recibiendo expresiones para todos de mis hijas, queda siempre de usted verdadero amigo y compañero muy su apasionado, Martín Fernández de Navarrete.

P. D. Tengo en Murcia a mi hijo Antonio ocupado en el arreglo, partición, etc., de las testamentarías de mi hermana María Teresa de Paz y su marido Perico Mayorga. La pronta muerte de este ha detenido aquí a Demetria que con dos niños iban a acompañarle y pasar en Murcia el invierno".

"Madrid, 27 de junio de 1834. Mi estimado amigo y consocio: Para usted que sabe la sinceridad de mi afecto y amistad y las relaciones antiguas de las familias de nuestras respectivas esposas ${ }^{42}$, es excusado que yo le explique el sentimiento que me cabe en el quebrantro que acaba de padecer porque sé por experiencia propia cuán intenso y prolongado es, y más quedando familia menuda ${ }^{43}$. A esto se añaden en usted los cuidados que

40. Se refiere a Pedro de Alcántara Musso y Pérez-Valiente, mariscal de campo.

41. Se refiere a Encarnación Musso y Fontes (1811-1883), hija primogénita de José Musso y Concepción Fontes, que se vio afectada con una enfermedad nerviosa como consecuencia de la separación de su marido, José María Melgarejo y Salafranca, V conde el Valle de San Juan, con el que contrajo matrimonio en 1830 y del que se divorció en 1849.

42. Da Manuela de Paz y Galtero y $D^{a}$ Concepción Fontes y Fernández de la Reguera eran ambas damas murcianas casi emparentadas.

43. Su esposa fallece en la epidemia del cólera morbo, el 19 junio de 1834, en Murcia. Antes, en marzo del mismo año, tuvo un parto complicado a causa de un niño que nació muerto. 
como Autoridad deben ocuparle con motivo de la propagación de la epidemia en esa Provincia ${ }^{44}$; cuidado que aquí tenemos ya, pues en Vallecas parece que hay casos, y las gentes van marchando de aquí a todas partes. La Señora de Gayangos me recomendó días pasados el asunto de que trata su adjunta carta que pendía un informe de usted. Yo creo que se perdió mi primera recomendación a usted, y ahora envío la cartita original que me escribió aquella Señora para que usted me diga lo que se ha de decir.

Dios saque a usted de tantos cuidados con felicidad y saludando a Encarnación y demás familia y también de parte de mis hijas, disponga usted como guste de su verdadero amigo, Martín Fernández de Navarrete".

"Madrid, 31 de octubre de 1834. Mi estimado amigo: Aunque las Ilagas que en el espíritu de usted y en el mío no es fácil que se borren durante la vida, vamos sobrellevando ésta entre otros cuidados que traen consigo los tiempos y las ocupaciones menos agradables de las que teníamos en nuestras Academias. Estas estuvieron suspensas durante la infausta temporada del cólera, porque todos huían de reuniones, las casa de la Panadería estuvo infestada y muchos enfermos o ausentes. Ya se han reunido ambas y la de la Historia la hemos remendado como se ha podido pues no habiendo más que tres académicos de número no pueden ni aún cubrirse los oficios. Ya trabajan algunos sus disertaciones para pasar a numerarios y así se irán Ilenando los vacíos que nos han dejado tantos y tan dignos y apreciables amigos nuestros. Dos González y un Clemencín no se reparan en un siglo.

Para el viernes 21 de noviembre tengo que leer el Discurso de estatuto pues concluye el trienio de mi Dirección y, como hay que dar cuenta en él del estado de los trabajos o empresas pendientes, quisiera que me usted me remitiese cuanto antes un apunte sobre la crónica de Fernando IV ya sea sobre lo que haya trabajado (en estos tres años), en su coordinación o ilustración, o bien en sus planes para abreviar la conclusión de esta obra en el estado en que se halla respecto a las confrontaciones y variantes de la Crónica, a sus ilustración con presencia de documentos y a la colección de estos inclusos en la parte impresa y otros que haya que añadir o citar, publicados recientemente en otras obras. Basta un apunte breve para mi objeto. Tenemos malo a nuestro apreciable D. Tomás González Carvajal y sus muchos años para entrada de invierno son débiles fiadores de su salud. Ayer tomó posesión en la española de académico Ángel Saavedra (Duque de Rivas) y nos leyó un bonito discurso de gracias.

Estoy ocupadísimo y me canso. Las cartas para Córdova caminarán. Expresiones a Encarnación y de parte de mis hijas. Mucho, mucho celebrara

44. Musso enfermó dos veces y se recuperó. Vuelto a la capital, tuvo que sufrir en octubre las consecuencias de una enorme riada que superó con creces el cauce del río Segura y asoló la huerta de Murcia. 
tener a usted aquí, pues sería un buen puntal para estas Academias. Cuídese usted como nos concierne y disponga sin limitación de su afectísimo y verdadero amigo y compañero, Martín Fernández de Navarrete".

\section{La Crónica de Fernando IV}

Ya hemos podido comprobar el interés de Fernández de Navarrete por que Musso le informe de los adelantos efectuados en el análisis de la Crónica. Por otro lado, si nos atenemos a cuanto anotan sus primeros biógrafos para seleccionar el trabajo académico más importante de José Musso Valiente, todos indican el mismo:

"la ilustración de la crónica del reinado de D. Fernando IV, que se le encomendó y sobre el cual, y especialmente sobre la regencia de su ilustre madre doña María La Grande, princesa acaso la más esclarecida que ha ocupado el solio castellano, escribió diferentes disertaciones que son un tesoro inapreciable. Trabajo acaso el más importante que salió de su pluma, porque más que ningún otro demuestra al razonador profundo, al narrador fácil y elegante, y da a conocer cuanto ha perdido la literatura nacional con un hombre que tanto hubiera podido realzarla. Materiales eran estos preparatorios para la historia de la vida de aquella insigne heroína a quien parecía llamado a vengar el agravio de los siglos y de la ingratitud de su nación" ${ }^{\prime 4}$.

Si contemporáneo era Fermín de la Puente, no menos lo era Francisco Cárdenas que fue profesor suyo en el colegio de los escolapios:

"Lugar es este de citar un pasaje del discurso leído en 28 de noviembre de 1834 a la Real Academia de la Historia por su director el excelentísimo señor don Martín Fernández de Navarrete. Véase la idea que daba una persona tan competente en la materia de los trabajos que desempeñaba Musso y que antes hemos mencionado: 'La Crónica, dice, del rey D. Fernando IV no ha podido tener en este periodo tan conocidos adelantamientos, porque la situación en que se ha encontrado el Sr. don José Musso, a quien la Academia encargó la coordinación de los muchos materiales, documentos y notas que se han reunido para ilustrarla, y sus asiduas ocupaciones como gobernador civil de la provincia de Murcia, no le ha permitido avanzar en este trabajo como deseaba. Sin embargo, después de coordinar y repasar de nuevo la colección diplomática y las demás noticias y apuntamientos que se le enviaron, ha anotado la Crónica aclarando algunos

45. Vid., Fermín de la Puente y Apezechea, Memoria biográfica de D. José Musso Valiente, Revista de Madrid, 1838. 
pasajes de ella, o deshaciendo equivocaciones por los mismos documentos que la han de acompañar; ha ordenado estos cronológicamente con los epígrafes que se echaban de menos; ha formado el índice de todos con la especificación debida en una tabla cronológica de los acontecimientos de aquella época. Preparado así, se promete el señor Musso concluir pronto su trabajo, como lo debemos esperar de su instrucción, de su activo celo por corresponder a la confianza de la Academia. Entretanto, ha procurado recoger los sellos que se usaron en aquel reinado para que se graben, así como los facsímiles de las firmas de él y de otros personajes, y de algún documento notable para que, como se ha hecho en la Crónica de don Enrique $I V$, sirvan estos adornos para satisfacer la curiosidad y para manifestar el estado de la paleografía española en estos diferentes periodos de nuestra historia. En la junta de 27 de noviembre de 1840, dijo el mismo Sr. don Martín Fernández de Navarrete: 'Los trabajos, arreglos y las confrontaciones de las crónicas de los reyes don Fernando IV y don Enrique IV, cuya continuación, según mi propuesta, ocupó los primeros meses del trienio, tuvieron que suspenderse por la falta de compañeros nuestros, pues el fallecimiento del señor don José Musso a mediados del año de 1838, y la ausencia del señor Lista, que fue elegido para la plaza de director del colegio de Humanidades de Cádiz, privaron las respectivas comisiones de la Academia de la laboriosos y útiles cooperadores, sin ser posible reemplazarlos hasta ahora. El señor Musso había leído en las últimas a que asistió varias observaciones críticas sobre los acontecimiento que refiere la crónica antigua de Fernando IV en los primeros años de su reinado, bajo la regencia de su esclarecida madre doña María la Grande, aquella heroína de quien decía el padre Flores que se necesitaban muchas planas sólo para apuntar las proezas de esta gran mujer, única en sus triunfos, por lo que no es extraño que el señor Musso, siendo su admirador, se propusiese dar noticia más amplia de sus hechos' ${ }^{\prime} .$. De propósito hemos copiado los pasajes siguientes para que se vea la importancia que daba la Academia de la Historia a los trabajos que había confiado al Sr. Musso, el ímprobo trabajo, la inteligencia y celo que requería, los multiplicados medios que empleó para asegurar su acierto y el más aventajado desempeño de ellos, y que, por último, ya se hallaban terminados cuando la Academia se ocupaba en su lectura y examen. Esto basta para la satisfacción de nuestros lectores y de todos los amantes de nuestra historia. Ahora podemos añadir, para que aquella sea más cumplida, que siguen el testimonio de una persona fidedigna, la Academia se propone publicar aquellos y otros trabajos del Sr. Musso en el primer tomo que vea la luz pública de sus importantes y eruditas memorias" ${ }^{\prime 4}$.

46. Francisco de Cárdenas, "Don José Musso Valiente", en Galería de españoles célebres contemporáneos o biografías y retratos de todos los personajes distinguidos de nuestros días en las ciencias, en las armas, en las letras y en las artes publicadas por D. Nicomedes Pastor Díaz y D. Francisco de Cárdenas, cit., pp. 299-301. 
El mismo Musso escribe unas letras sobre este trabajo:

"La de la Historia, con noticia de que quería reunir materiales para hacer el elogio histórico de la de doña María la Grande, me encargó la revisión y arreglo de la crónica de Fernando IV con todos los documentos pertenecientes a aquel reinado, con cuyo fin me entregó todo bajo inventario, dándome las instrucciones necesarias ${ }^{\prime \prime 4}$.

A partir de aquí, se producen unos interrogantes para los que buscamos una respuesta convincente, todos destinados a conocer hasta dónde llegó la investigación de Musso y a la localización de los textos por él redactados según extraemos de la lectura de su Diario.

Si nos atenemos a lo que en palabras del mismo Musso acabamos de leer, el interés radicaba en el elogio de Doña María de Molina, como continuación quizá del de la reina Católica que Clemencín había realizado $(1820)^{48}$. Siendo esto así, quedaría claro que el interés desmedido que mostraba Martín Fernández de Navarrete por la investigación y análisis de esta crónica que, como maldición, ninguno de los autores principales pudo ver publicada en vida, ni Musso, ni Salvá, ni, por supuesto, Navarrete, se debería a la búsqueda de cuanto pudiera enriquecer la actividad política de la regente medieval, no al estudio de la dicha crónica en sí misma.

Aproximadamente, nuestra investigación se dirige al hallazgo de respuestas convincentes a cuantos interrogantes planteamos en los puntos siguientes:

$\left.1^{\circ}\right)$ Musso dejó un texto escrito que aún no ha llegado a nosotros: en su ingreso como académico numerario de la Real Academia de la Historia, diserta sobre Ilustración a las Cortes de León y Castilla, en el año 1837. Así lo anota Antonio Ballesteros y Beretta en su Historia de España y su influencia en la historia universal, Barcelona, Salvat, 1918. Su hallazgo49 nos permitirá conocer si fue un adelanto de su investigación o un análisis completo, aunque, a priori, creo más en la existencia de una exposición hasta donde investigó, 1297, año en el que llegó en 1837. No sabemos en estos momentos qué pudo investigar en el año siguiente pues fue el de su fallecimiento y falta el Diario de este año.

47. Cfr., José Musso Valiente, "Memorial de la vida", en (José Luis Molina Martínez, coord.), Obras, cit., vol I., p. 486.

48. Para este asunto, vid., Antonio López Ruiz-Eusebio Aranda Muñoz, Diego Clemencín, Murcia, Real Academia Alfonso X el Sabio, 1994, pp. 101-123. Para una visión moderna del tema, vid., Elena Maza Zorrilla, Miradas desde la Historia. Isabel la Católica en la España contemporánea, Valladolid, Ámbito Editorial, 2006; VV. AA., Isabel la Católica vista desde la Academia, Madrid, Real Academia de la Historia, 2005.

49. El discurso habrá de buscarse en las Actas de la corporación o en las Memorias de la misma que cita Musso en su Diario, si es que aún existen. 
Para aclarar este punto, contamos con el informe que efectúa Marcial Antonio López para la R. A. H. y que transcribimos seguidamente:

"Academia de 29 de diciembre de 1837. Con el Revisor General: y queda en consecuencia el Sr. D. José Musso y Valiente declarado individuo de número.

El Revisor General ha visto los trabajos del Sr. D. José Musso, que nuestra Academia tuvo a bien se le pasasen, con objeto de que sirvieran para su admisión a la plaza de número. Son de dos especies: unos contienen observaciones sobre la crónica del Rey D. Fernando IV, otros sobre los Concilios de León y Coyanza.

Para poder juzgar más acertadamente, hubiera deseado el que suscribe la parte de texto de la crónica a que se refieren los primeros; pero, si esto no ha sido posible por estarse ocupando de ella la Comisión, puede asegurar que las observaciones son en su concepto oportunas, hechas con crítica y sobre asuntos cuya investigación debe llamar la atención del investigador y del filósofo, como son las célebres Carta de hermandad de los pueblos de Castilla; el conocimiento de sus propias fuerzas y lo que valían; la organización de los Cuerpos Municipales; el nombramiento de los Jueces; la Legislación de aquel tiempo; los límites del poder de la Corona; el de los Señores y Magnates; el del Clero; no tan fuertes en contraposición de los pueblos como se creía; pudiendo las juiciosas y meditadas observaciones que se hacen sobre todos estos particulares, conducir al que sepa leer la Historia, a investigaciones de grandes momentos y de no menor consecuencia, tanto para la formación de la leyes políticas y civiles, como para la mejor administración de la justicia.

Respecto a los trabajos que han tenido por objeto los Concilios de León y Coyanza, la Academia, que ha leído con satisfacción su lectura, ha sido ya Juez acaso. Los análisis que de ello se hacen han renovado al que suscribe a leerlos por sí mismo y las mismas ideas que ya concibió cuando tuvo el gusto de oírlas. No puede menos de verse con el más grande interés, el origen de los Fueros de los primeros pueblos de la Monarquía Española, por cuyo tipo fueron recibiéndolos otros sucesivamente; las primitivas semillas del régimen Municipal que no tuvieron, por cierto, tan pronto como muchas Naciones que hoy nos aventajan; los elementos del poder judicial; la extensión que en aquella remota época tenía el de la Corona; los Códigos que regían; las costumbres de nuestros mayores; el modo de terminar sus diferencias, haciendo de árbitros a los Reyes; los tribunales ordinarios y de la Corte del Rey; las trabas que tenía la propiedad; entonces el limitado poder de la feudalidad, en todas partes más arraigada que en España, y estos puntos y otros de menor momento se hallan tratados con detención, con ingenio y de un modo que manifiestan el mérito de su autor. 
Por lo mismo, y porque la Academia se halla en el caso de premiar los trabajos que la aplicación de sus individuos hace con tanto fruto y por llenar los debates del Instituto de un modo digno de ella, juzga el Revisor que los que ha presentado el Sr. Musso le hacen acreedor a que se le declare individuo de Número. La Academia resolverá son embargo como siempre lo más acertado.

\section{Madrid, 29 de diciembre de 1837 \\ Marcial Antonio López"}

$2^{\circ}$ ) En la Comisión de Colección de Cortes de la Academia se encontraba, junto a Musso, Miguel Salvá y Munar50. Por la Biblioteca de la Real Academia de la Historia. Guía,51 conocemos que ingresa este fondo en la Academia en enero de 1835 y que existe un legado con el nombre de Vicente Salvá compuesto de 46 vols., signatura: 9/4263-4307, que contienen leyes, fueros y otros documentos referentes a las Cortes de Castilla y León (Ss. XI-XVIII), originales y copias, y que "aunque esta colección lleva el nombre de este conocido librero no consta que fuese reunida por él. Parece que fue comprada por el Gobierno para la Junta de Aranceles de donde se trajo a la Academia". Consta su descripción en el Catálogo general de manuscritos de la Real Academia de la Historia, de Antonio Rodríguez Villa (1843-1912)52.

A este respecto, poco queda por descubrir, pues, tras la lectura de las anotaciones de Musso en su Diario, podemos deducir que la Colección Salvá apenas incide en la Crónica de D. Fernando IV, más bien se utiliza y sirve para la Colección de Cortes, anotaciones de Musso que también hemos recogido. Además, Salvá estaba con él, o al revés, que lo mismo da, en este segundo apartado, pues los trabajos de la Crónica eran personales por muchas comisiones de control que le pusiesen. Tanto a Salvá como a Musso, estos trabajos le valieron para ascender a académicos de número.

$3^{\circ}$ ) También se encuentran en la Real Academia de la Historia un Legajo en folio con copias que sirvieron a D. Antonio Benavides para ilustrar la Crónica de este Monarca [Fernando IV: 11-8-3-leg. 9 (Ant.) / 11-8-8-1437 / 9-6484], y Papeles y correspondencia de Fernández de Navarrete, Flores y otros Académicos para publicar la Crónica de Fernando IV de Castilla [11-1-6-leg. 9 (Ant.) / i114-3-834? La Crónica de Fernando IV se publicó en 1860 sin el nombre de

50. Al citar Musso sólo por Salvá a su compañero de comisión, se puede caer en el error de pensar en Vicente Salvá, pues sus papeles Ilegan a la Academia en 1835.

51. Se puede ver en [Documento en línea], Dirección URL: <http://www.rah.es/pdf/guiaBiblioteca.pdf>. [Consulta: 23 diciembre 2006].

52. Se puede consultar en [Documento en línea]. Dirección URL: <http://www.rah.es/pdf/ o14635.pdf.>. [Consulta: 30 diciembre 2006]. 
Musso, aunque con el uso de sus papeles, con Antonio Benavides Fernández de Navarrete como autor. ¿Qué no corresponde a su autoría? No hemos tenido la oportunidad de conocer aún estos documentos, por lo que aún no podemos exponer un juicio correcto y ajustado. De todos modos, sabemos por el Diario que Musso, en 18 de diciembre de 1836, estaba leyendo el Capítulo IX de la Crónica y examinando documentos correspondientes al mes de diciembre de 1297. Hasta ahí, pues, la investigación pudo ser aprovechada puesto que era de la Academia.

En el Expediente Musso de la R.A.H. hemos encontrado otro apunte:

"Año de 1837, nombramiento de Académico. Los trabajos sobre los Fueros de León y Oviedo, en cuya virtud pasó, se remitieron a la comisión de la crónica de Fernando IV en $1^{\circ}$ de junio de 1845".

Ya, pues, no cabe duda de que sus trabajos se utilizaron en la redacción final de la Crónica.

Sin embargo, Antonio Benavides, en sus Memorias de D. Fernando IV de Castilla, oculta todo esto o, siendo benevolentes, no explicita nada de la cuestión. Se refiere en el capítulo siguiente a la Crónica, "llustraciones", a explicar que en 1814 la Colección Diplomática tocaba a su fin. Y continúa:

"En el [año] de 1827, la nueva comisión, compuesta de los Sres. Navarrete, Clemencín, Ceán Bermúdez, Padre La Canal, Solanot, y sucesivamente lo de los Sres. Sabau, Argüello, Siles, Muro, Clonard, Baranda, Banqueri, después de confrontar gran número de documentos, pedir otros nuevos, consultar repetidas veces la España Sagrada, La Historia de León del Padre Risco y las historias de las ciudades y villas de los reinos, sin decaer el ánimo, sin disminuir su aliento a pesar del trabajo, llegó a conseguir ver impresa la Colección. Lástima grande fue que los resultados no correspondiesen a los esfuerzos empleados, pues la Colección se imprimió diminuta, con documentos duplicados, con las datas erradas, y para que nada faltase, hasta con la foliatura equivocada. Cuando la Academia volvió los ojos a la Crónica de Fernando IV, cuyos trabajos andaban más que descuidados desde el año de 1838, determinó oportunamente imprimir de nuevo la Colección, y desde entonces hemos procurado purgarla de los vicios capitales de que adolecía, aumentándola al mismo tiempo con gran copia de documentos de señalado interés" ${ }^{\prime \prime 53}$.

53. Vid., Memorias de D. Fernando IV de Castilla. Tomo I. Contiene la Crónica de dicho Rey copiada de un códice existente en la Biblioteca Nacional, anotada y ampliamente ilustrada por D. Antonio Benavides, individuo de número de la Real Academia de la Historia, por cuyo acuerdo se publica. Madrid: imprenta de José Rodríguez, calle del Factor, núm. 9. 1860, p. 246. 
Como se habrá observado oculta el trabajo de Musso. Porque no queremos pensar que le dirige estas aceradas palabras:

"Hemos hallado al hacernos cargo de los Mss. pertenecientes a esta Crónica un sinnúmero de papeles, los más inútiles, otros que han necesitado nuevos estudios para sacar de ellos algún provecho, y algunos pocos que nos han servido de grande utilidad" ${ }^{\prime 24}$.

Entre los de utilidad cita el discurso sobre la cronología del reinado, del académico Manuel Acosta; unos apuntes del Padre Alamanzor (sic); unas observaciones hecha por Juan Fernández y otras remitidas por Joaquín Antonio Camino. $Y$ concluye:

"He aquí todo lo que hemos podido sacar en limpio del fárrago de papeles que se nos entregó para llevar a cabo una obra que con impaciencia espera el público hace ya medio siglo" ${ }^{\prime \prime 5}$.

Antonio de Benavides era sobrino de Martín Fernández de Navarrete, quien encarga el trabajo a Musso, cuya vida económica dependía de los trabajos que efectuaba en las distintas comisiones de las distintas academias a las que pertenecía. Esto significa que hacía los trabajos por encargo del tipo que fuesen y que va a ser casi imposible determinar los que hizo sin que constase su firma, los utilizasen otros o no. Pero, no se puede dudar del esfuerzo que realizó que fue, en general, aplaudido.

$4^{\circ}$ ) La lectura de las Actas de las sesiones académicas pueden arrojar luz suficiente para añadir datos que completen cuanto Musso anota en su Diario y tener otra perspectiva de juicio sobre el desarrollo de esta comisión que le encargó la Academia.

$\left.5^{\circ}\right)$ Si se tiene en cuenta la anotación de Musso en su Diario de 9 de noviembre de 1837, Alberto Lista también recoge el fruto de la investigación de Musso ${ }^{56}$.

"Tuvo una verdadera satisfacción el señor Lista, cuando las circunstancias le permitieron dejar el cargo penoso e ingrato de director de la redacción

54. Ibid., p. 247.

55. Ibid., p. 247.

56. En el Memorial de la vida de Musso Valiente, podemos leer lo siguiente: "Lista ha sido desde entonces una de las personas que me han tratado con más franqueza; entró por mediación mía en la Academia Española y de la Historia; me regaló algunas composiciones poéticas, dirigidas las más de ellas a mi hija Encarnación; siguió correspondencia conmigo mientras estuvo en Francia y, en el día, continuamos tratándonos con amistad" [vid., en José Musso Valiente (José Luis Molina Martínez, ed.), Obras, Murcia, Ayuntamiento de Lorca-Universidad de Murcia, 2004, vol. I]. 
de la Gaceta. [...] Como el que le sucedió en la dirección de la Gaceta era un íntimo amigo suyo, que había recibido aquel cargo en virtud de contrata celebrada con el gobierno, el señor Lista le suministraba con frecuencia artículos y cuantos le encomendaba para hacer más instructiva e interesante la lectura del periódico oficial. Entre aquellos, es muy notable una serie de ellos en los que, con ocasión de los cuadernos de Cortes que publicaba la real Academia de la Historia, se propuso examinar los elementos de las instituciones de la corona de Castilla, así como el espíritu de los fueros y privilegios de sus ciudades ${ }^{57}$. Esta serie de artículos es una obra de singular mérito, y de tanto que la misma real Academia encargó al señor Lista que los leyese en varias de sus sesiones, como trabajo presentado a la misma para ser admitido en clase de académico de número, como lo fue en efecto $^{\prime \prime 58}$.

Para conocer hasta dónde 'copia' las notas de Musso, habría que leer los referidos artículos que publica Lista en la Gaceta. Porque son muchos los que se benefician de la generosidad de Musso, el único trabajador, en este caso su amigo Lista para ser elegido académico de número. ¿Elige Lista para su discurso de ingreso en la Academia este tema porque no le ocasiona mucho trabajo o porque obedecía a un plan propiciado por Navarrete? Muchas interrogantes son que, en definitiva, no nos deben distraer de la verdadera: ¿hasta dónde llegó Musso en la investigación sobre la crónica? ¿Utilizó ese trabajo Antonio Benavides?

$\left.6^{\circ}\right)$ Miguel Salvá y Munar (1792-1873) es elegido numerario el 29 de abril de 1836. Para este acto, lee un discurso titulado Ilustración a las Cortes de León de 1820 y de Coyanza de 1050. Este discurso se le atribuyó por sus primeros biógrafos a Musso, quizá por la semejanza titular. ¿Le 'prestó' el tema Musso? Abre, pues, el abanico de posibilidades en la maraña investigadora este discurso y surgen nuevas interrogantes: ¿por qué tantas personas en el mismo tema? ¿Había en ello algo más que el mero interés personal de ser académico de número?

Así que, con todo este material, podemos intentar la solución de este pequeño enigma que sólo tiene por objetivo saber en qué grado Musso Valiente participó en este empresa, como acabo de dejar escrito.

57. La cursiva, que no aparece en el original, me permite señalar un aspecto que en estos momentos interesa indicar.

58. Vid., "D. Alberto Lista", en Galería de españoles célebres contemporáneos o biografías y retratos de todos los personajes distinguidos de nuestros días en las ciencias, en las armas, en las letras y en las artes publicadas por D. Nicomedes Pástor Díaz y D. Francisco de Cárdenas. Tomo VIII. Madrid. Imprenta y librería de D. Ignacio Boix, editor, calle Carretas números 8 y 35. 1845, p. 52. 
La representación en 23 de julio de 1837 de Doña María de Molina, de Mariano Roca de Togores, viene a consolidar una intencionalidad: el paralelismo entre el reinado de esta reina y el de Isabel II $^{59}$. La actitud de Musso con relación a la obra de Roca de Togores Doña María de Molina, al intentar por todos los medios en sus manos evitar que sea esa precisamente la 'lectura' que haga el público ${ }^{60}$, para lo que escribe un par de artículos sobre la Edad Media por si puede contrarrestar en la opinión pública la conclusión de Donoso, demostrando que era un tema típicamente medieval, indica que él al menos sólo entraba en el asunto desde un punto de vista meramente académico ${ }^{61}$, quizá por ese 'miedo' que, tras su experiencia en cargos públicos, sentía por si destapaban su 'pasado', es decir, los errores cometidos durante su mandato como primer alcalde constitucional de Lorca en el Trienio, asunto no muy claramente resuelto ${ }^{62}$, pues persisten algunos interrogantes en su conducta. Queda así pendiente una investigación a realizar en la Biblioteca del Congreso y posiblemente en el Ministerio que fue de Fomento en el que quizá se puedan encontrar las capitulares municipales de Lorca que se enviaron a Madrid a la conclusión del Trienio. También se ha de localizar el expediente que se pudo llevar a cabo por la Audiencia de Granada con relación al juez Eraso, si no se encuentra en Madrid.

59. Vid., Tana García Mínguez, "El drama histórico Doña María de Molina en el Diario de José Musso Valiente", en (Manuel Martínez Arnaldos, José Luis Molina Martínez, Santos Campoy García, eds.) José Musso Valiente y su época (1785-1838) La transición del Neoclasicismo al Romanticismo, dad de Mucia-Ayuntamiento de Lorca, Murcia, 2006, vol. II, pp. 487-496.

60. Evidentemente no lo consigue. En El Panorama, periódico de Madrid, en su n ${ }^{\circ} 1$, de fecha 29 de marzo de 1838, en las páginas 10-12, aparece un artículo titulado Doña María de Molina, firmado por José Muñoz Maldonado, que se inicia de la siguiente manera: "La España presentaba a fines del siglo XIII una situación muy parecida a la actual del siglo XIX. Una mujer, una Reina gobernaba la monarquía, servía de escudo a un niño Rey, cuyo trono intentaba usurpar un infante tío suyo, y rodeándose de las cortes del reino sacrificaba su fortuna para sostener la causa de la legitimidad. Hoy también una mujer, una Reina gobierna la monarquía, sirve de escudo a una niña Reina, cuyo trono intenta usurpar un infante tío suyo, y llamando en su derredor la ya olvidada por tantos siglos representación nacional, emplea toda su fortuna en levantar batallones, y procurar recursos a los defensores de la legitimidad y de la libertad que se halla unida a ella. ¡María de Molina es pues un personaje cuyo retrato es dado a conocer a los españoles no sólo en la historia, sino en el mismo trono de la augusta GOBERNADORA del reino!".

61. Aparecen esos artículos en La España con el título de Estudios de la Edad Media, uno en el $n^{\circ} 52,24$ de agosto de 1836, y el segundo en el $n^{\circ} 66,5$ de septiembre del mismo año.

62. Vid., Domingo Munuera Rico, "Los de los años 1822-1823, tiempos borrascosos en la vida de José Musso", en (M. Martínez Arnaldos-J. L. Molina Martínez-S. Campoy García, eds.) José Musso Valiente y su época (1785-1838). La transición del Neoclasicismo al Romanticismo, cit., p. 121-127. 
Bien es verdad que Clemencín estaba en esta línea ${ }^{63}$, la de los elogios a las reinas importantes, y con él, quizá, toda la Academia, pero no nos olvidemos de que Martín Fernández de Navarrete era el principal impulsor del estudio y análisis de la Crónica de Fernando IV en el sentido que hemos dejado indicado.

Por otro lado, aunque sea de modo sesgado, se producen dos hechos, esta vez de tipo literario, manifestadores de la misma ideología, al menos el primero, porque, en el caso de Bretón, pienso en la oportunidad de escribir un drama histórico que pudiera ser continuación del de Roca de Togores. Me refiero al drama histórico del Marqués de Molins, que después sería largos años Director de la R. A. E., Da María de Molina y a la obra teatral de Bretón de los Herreros Fernando IV el Emplazado.

En el Diario de Musso podemos leer algunas anotaciones que apenas aumentan las noticias amistosas de ambos intelectuales y que anotamos por simple curiosidad.

\section{6}

\section{Enero}

Día 18. Visitas. A Navarrete. Hablamos del sello de la Academia y viñeta para los títulos. Asimismo de proporcionar a Revilla la entrada en la Academia Española, \&. A Mesonero, con quien repetí la de ayer tarde a casa de la viuda de Gámez y, repasando de nuevo las listas sobre libros, hemos separado algunos.

\section{Marzo}

Día 22. Visitas. A Mesonero, para tratar de la suscripción de los periódicos y arreglo de la biblioteca del Ateneo ${ }^{64}$. Le referí la noticia que me escriben de Lorca y quedó escandalizado. "Esta gente, dijo, se va circunscribiendo a ellos solos. Ya han echado a Pontejos y lo mismo hacen con todos los que les hacen sombra". Esta tarde, en paseo, me dijo que Gallardo deseaba conocerme y ver mi discurso de recepción en la Academia española. Le rogué le diese gracias e hiciese presente que tal vez se ofrecerían dificultades para sacar de la Academia el discurso. A Navarrete, que se estaba vistiendo de gala para ir a la sesión regia y, aparentando incomodidad, disimulaba algún tanto el gusto que le causaba verse con tanto bordadito y crucecita. -"Vamos, le dije. ¿Podremos ver esas viñetas para que nos sirvan de gobierno en la que ha de hacerse para los títulos de la Academia de la Historia?" -"Al instante. Aquí las tengo a mano". Las buscó

63. El que Clemencín escribiera el elogio de la reina Católica sólo indica una tendencia con la que hacía patria. Sin embargo, emprender el elogio de Da María de Molina tenía otras connotaciones que son las que hemos comentado: el paralelismo con la situación de la Regente.

64. Para todo lo relacionado con esta institución, vid., José Luis Molina Martínez, "El Ateneo de Madrid en el Diario de José Musso Valiente (Lorca, 1785-Madrid, 1838)", conferencia pronunciada en dicho Ateneo. 
largo tiempo y no encontró ninguna, pero me refirió ciento y una historias de ciertos personajes a quienes no conozco; $y$, en esto, avisan estar a la puerta el coche del obispo de Huesca que venía por él. Sic me servavit Apollo65.

\section{Junio}

Día 23. Conferencia con Navarrete. Me ha dicho que el difunto D. Tomás González, archivero de Simancas, había demostrado ser falsa la especie de que el Emperador Carlos V se había mandado hacer las exequias en vida, que lo que hubo fue que mandó hacerlas magníficas a su mujer.

Octubre

Día 14. Visita de Lista. [...] Tratándose de las Academias y de los académicos, dijo que Navarrete, buen escritor en cuanto a estilo y lenguaje, semeja a una caballería cargada de materiales para que otros hagan las obras.

A partir de aquí, aunque Musso siga asistiendo a las Academias a que pertenecía, sus intereses iban variando. Se aleja de las instituciones oficiales, se acerca al Liceo, se dedica a la práctica religiosa, sufre la pérdida de su hija menor, Ana, asiste a una perdida de salud que lo lleva a la muerte y no poseemos anotaciones en el Diario correspondientes a 1838. Es decir, se inicia en vida un ocultamiento que, aun buscado, le ha perseguido desde entonces.

Hemos, pues, mostrado a ambos personajes inmersos en una relaciones humanas propiciadas por ámbitos comunes en lo intelectual y vistos dos proyectos en los que ambos académicos están implicados: en uno se observa una disparidad de criterio; en el otro Musso se nos presenta como el brazo ejecutor de una idea de Navarrete, investigación aún no conclusa por nuestra parte y que esperamos cerrar en cuanto consigamos los documentos en los que creemos se puede hallar la solución de cuanto se refiere a la Crónica de Fernando IV el Emplazado.

65. No deja de haber cierta ironía en el comentario de Musso. 


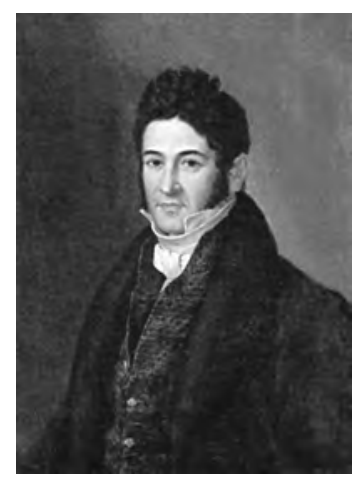

Figura 3: José Musso Valiente.

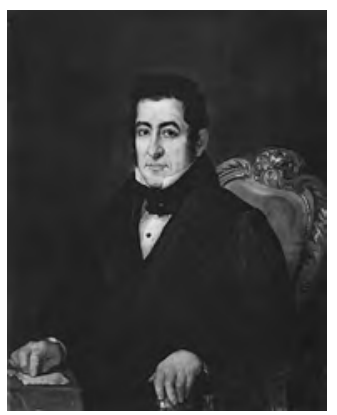

Figura 4: José Musso Valiente. Retrato al óleo existente en la Real Academia Española (posiblemente de José Gutiérrez de la Vega, 1837). 